\title{
Natural antioxidant vitamins: A review of their beneficial roles in management of diabetes mellitus and its complications
}

\author{
Ademola Ayeleso ${ }^{1 *}$, Nicole Brooks ${ }^{2}$, Oluwafemi Oguntibeju ${ }^{3}$ and Emmanuel \\ Mukwevho ${ }^{1}$ \\ ${ }^{1}$ Department of Biological Sciences, North West University, Mmabatho, ${ }^{2}$ Department of Wellness Sciences, Cape Peninsula \\ University of Technology, Capetown, ${ }^{3}$ Oxidative Stress Research Centre, Department of Biomedical Sciences, Cape Peninsula \\ University of Technology, Bellville, South Africa
}

*For correspondence: Email: ademola.ayeleso@gmail.com; Tel: +27840171248

\begin{abstract}
Diabetes mellitus is a complex and progressive metabolic disease which is associated with multiple complications. Chronic hyperglycaemia is the defining characteristic of diabetes mellitus. Hyperglycaemia leads to generation of free radicals and induces oxidative stress, which has become the chief factor that leads to diabetic complications. This review supports the use of antioxidant vitamins as therapeutic agents in the management of diabetes mellitus and its complications, and also provides an insight into the potential pharmacological effects of natural antioxidant vitamins in diabetic conditions. These antioxidant vitamins can be used as safe supplements to manage the occurrence and complications of the disease. Selected studies have reported on the beneficial effects of antioxidant vitamins in experimental models. The involvement of oxidative stress in diabetes and its complications has made the use of natural antioxidant vitamins (free radical scavengers) from plants inevitable as they may be very effective and safer in the management of diabetes.
\end{abstract}

Keywords: Antioxidant, Oxidative stress, Vitamins, Diabetes mellitus

Tropical Journal of Pharmaceutical Research is indexed by Science Citation Index (SciSearch), Scopus, International Pharmaceutical Abstract, Chemical Abstracts, Embase, Index Copernicus, EBSCO, African Index Medicus, JournalSeek, Journal Citation Reports/Science Edition, Directory of Open Access Journals (DOAJ), African Journal Online, Bioline International, Open-J-Gate and Pharmacy Abstracts

\section{INTRODUCTION}

Diabetes mellitus (DM) is a complex disease with multiple etiologies characterized by hyperglycaemia [1]. In DM, lack of biologically active insulin results in the impairment of uptake and storage of glucose and reduces usage of glucose for energy purposes [2]. Deficiency of insulin leads to derangement in carbohydrate metabolism and reduces the activities of a number of key enzymes, including glucokinase, phosphofructokinase, and pyruvate kinase [3,4]. It has been reported that more than 347 million people worldwide have diabetes [5] and the metabolic disease has been projected to become the 7 th leading cause of death in 2030 [6].

DM is usually categorised into two major types i.e. type 1 (insulin-dependent diabetes mellitus, IDDM) and type 2 (non-insulin dependent diabetes mellitus, NIDDM) [7,8]. Type 1 diabetes is caused by the autoimmune destruction of insulin-producing beta cells in the pancreas. Type 2 diabetes arises because the cells become resistant to the action of insulin or the body cannot make enough insulin. The most frequent and key symptoms of DM are hyperphagia, polyuria, polydipsia and reduced 
body weight $[9,10]$. Diabetic condition is chronic and requires constant supervision, education and monitoring [11].

Despite tremendous efforts in the control the prevalence of DM, its manifestations results in human suffering and high economic cost [12]. Oxidative stress, which is caused as a result of excessive production of reactive oxygen species (ROS) is increased in DM [13] and leads to oxidative damage of biomolecules i.e. lipids, proteins and DNA [14]. Antioxidant vitamins such as vitamin $A$ (i.e. beta carotene), $C$ and $E$ are part of the physiological non-enzymatic defense against oxidative stress [15]. This review covers the potential roles of natural antioxidant vitamins in the management of diabetes and its complications.

\section{DIABETES MELLITUS AND OXIDATIVE STRESS}

Free radicals are reactive molecules possessing unpaired electrons and are very unstable. They trigger chain reactions which lead to the oxidation of macromolecules in order to have stability [16]. ROS such as hydrogen peroxide $\left(\mathrm{H}_{2} \mathrm{O}_{2}\right)$, superoxide $\left(\mathrm{O}_{2}{ }^{\circ}\right)$, singlet oxygen $\left(1 \mathrm{O}_{2}\right)$, and the hydroxyl radical $(\cdot \mathrm{OH})$ ] and reactive nitrogen species (RNS) which include peroxynitrite anion $\left(\mathrm{ONOO}^{-}\right)$, dinitrogen trioxide $\left(\mathrm{N}_{2} \mathrm{O}_{3}\right)$, nitroxyl anion $\left(\mathrm{HNO}^{-}\right)$and nitric oxide (NO) are examples of the reactive molecules [17]. Oxidative stress is caused by increased production and/or reduction in the removal of reactive species by the antioxidant defences [18]. Abnormal elevated levels of free radicals and the simultaneous reduction of antioxidant defence can result in damage of cellular organelles and enzymes, increased lipid peroxidation and development of insulin resistance [19].

Diabetes is known to be also associated with oxidative stress. Hyperglycaemia results to the production of free radicals by auto-oxidation of glucose, non-enzymatic glycosylation and augmented polyol pathway [20-23]. Oxidative stress plays a pivotal role in diabetes-induced metabolic abnormalities [8,24]. Increased oxidative stress activates the nuclear redoxsensitive transcription factor $\mathrm{KB}$ that upregulates genes such as cytokines, adhesion molecules, endothelium-1, and procoagulant tissue factor which trigger the development of chronic diabetic complications $[25,26]$. Some of these diabetic complications include diabetic neuropathy (disease or abnormality of the nervous system) [27], diabetic retinopathy (eye disease i.e. cataract formation in the lens) [28], diabetic nephropathy (kidney disease) [28,29], diabetic hepatopathy (Liver disease) [30], diabetic cardiomyopathy (disease of the heart muscle) [31] and reproductive damage [32].

\section{OVERVIEW OF ANTIOXIDANT VITAMINS}

Vitamins (combination of two words: vital amines) are complex organic substances that are needed by the body in small quantities. These are found in minute quantities in food, in some cases are produced by the body, and are also produced synthetically. Vitamins are divided into two major groups: the fat-soluble vitamins (vitamin $A$, vitamin $D$, vitamin $E$, and vitamin $K$ ) and the water-soluble vitamins which include vitamin $\mathrm{C}$ and the group of molecules referred to as the vitamin B complex. Each of them has its own special role in the development of human body.

Among the different classes of vitamins, vitamins $A, C$ and $E$ are referred to as antioxidant vitamins. Vitamins $A, C$, and $E$ are derived from diets which detoxify free radicals directly and also interact in recycling processes to create reduced forms of the vitamins [47].

Vitamin A, a lipid-soluble vitamin is an isoprenoid compound with a 6-membered ring and an 11carbon side chain and is found in plants as a provitamin called $\beta$-carotene (Figure 1 , the most abundant carotenoid which can be converted to vitamin $A$ by an oxygenase present in the intestine [33]. $\beta$-carotene has antioxidant properties that can help neutralize free radicals [34]. It remains the major source of vitamin A in the body and plays a significant role in maintaining the health of cells. Vitamin $A$ is an essential nutrient needed for normal growth, reproduction, embryonic development, vision and immune function [35]. $\beta$-carotene can be found in food sources such as carrots, sweet potatoes and apricots. Vitamin A deficiency can lead to two major disorders like: night blindness and drying of the skin.<smiles>CC1=C(/C=C/C(C)=C/C=C/C(C)=C/C=C/C=C(C)/C=C/C=C(C)/C=C/C2=C(C)CCCC2(C)C)C(C)(C)CCC1</smiles>

Figure 1: Structure of $\beta$-carotenes 
Vitamin C (Figure 2), also known as ascorbic acid, is a water soluble vitamin and is not easily stored in the body. It is needed for the growth and repair of tissues in all parts of the body and also helps the body make collagen, an important protein used to make skin, cartilage, tendons, ligaments, and blood vessels. It is a well-known antioxidant that efficiently scavenges free oxygen radicals [36]. The presence of an enediol group in the structure of vitamin $\mathrm{C}$ allows electron availability and makes it a member of an oxidation-reduction system with electrondonating or accepting potential [37]. The richest natural sources of vitamin $C$ are fruits and vegetables. Vitamin $\mathrm{C}$ deficiency symptoms include scurvy, decreased wound-healing rate, nosebleeds and a reduced ability to fight infection.

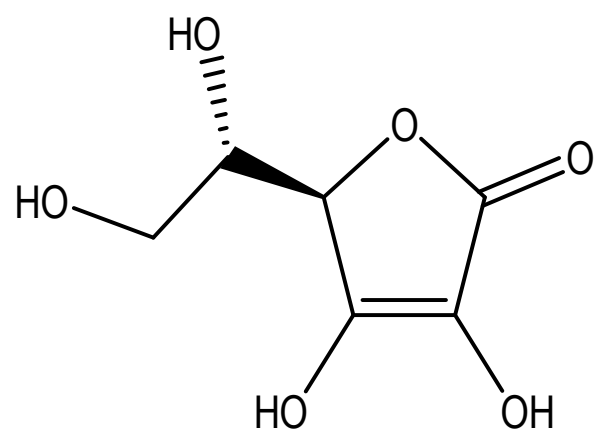

Figure 2: Structure of vitamin $\mathrm{C}$

Vitamin $E$ is a fat-soluble vitamin which include four tocopherols ( $\alpha, \beta, \delta, \gamma)$ and four tocotrienols $(\alpha, \beta, \delta, \gamma)$ [38]. It helps in the prevention of oxidation and formation of red blood cells in the body. It also assist in the protection of the lungs from becoming damaged by polluted air. This vitamin can be found in whole grains (such as wheat and oat), wheat germ, leafy green vegetables, sardines, egg yolks, nuts, bread, cereals and seeds. The deficiency of this vitamin can cause many diseases like cancer, diabetes, heart disease, and Alzheimer's disease. Both tocopherols (Figure 3) and tocotrienols (Figure 4) are important components of biological membranes having both antioxidant and nonantioxidant effects [39]. It is essential for the inhibition of oxidation in body tissues, formation of red blood cells and prevention of the breakdown of body tissues. Vitamin $E$ has proved to be effective in preventing lipid peroxidation and other radical driven oxidative events [38]. In the membrane-water interphase, the reaction between vitamin $E$ and lipid radical takes place and vitamin $\mathrm{E}$ donates a hydrogen ion to lipid radical resulting in tocopheroxy radical formation which is regenerated back to its reduced form by vitamin $\mathrm{C}$, reduced glutathione and coenzyme $Q$ [39]. The cells alleviate the effects of oxidative stress through different means by eitherrepairing the damage (damaged nucleotides and lipid peroxidation by-products) or directly reducing the pro-oxidative state via enzymatic and non-enzymatic antioxidants [40].<smiles>[R]c1c([R])c2c(c([R])c1O)CCC(C)(CCCC(C)CCCC(C)CCCC(C)C)O2</smiles>

Figure 3: Structure of tocopherols<smiles>[R]c1c([R])c2c(c([R])c1O)CCC(C)(CC/C=C(/C)CC/C=C(\C)CCC=C(C)C)O2</smiles>

Figure 4: Structure of tocotrienols

\section{ANTIOXIDANT VITAMINS AND DIABETES}

The fight against free radicals in the body is mediated by the actions of antioxidants [41] andmuch interest on the use of natural antioxidants as a means to prevent oxidative damage in diabetes has also developed [42]. Though, there are not much studies from available literature on the efficacy of antioxidant vitamins on people with diabetes however, some researchers have shown their beneficial effects on diabetes clinical trials. On the other hand, many studies using animal models have shown the potency of antioxidant vitamins to combat diabetes and its complications. The combination of Vitamin A and insulin could protect the heart against the damaging effects of diabetic-induced pre-oxidative stress [43]. It has been shown that vitamin A supplementation could improve wound healing even in the absence of insulin and this indicates that vitamin A may be useful in wound management of insulin-resistant diabetic patients [44].

Treatment with $\beta$-carotene (a precursor of vitamin A) distinctly led to the prevention of thermal hyperalgesia and cold allodynia in streptozotocin induced diabetic rats (45) and had ameliorating effects on oxidative stress and nephropathy in diabetic rats [46]. The treatment with $\beta$-carotene increased hepatic glutathione levels and also reversed the increased cardiac and renal levels of lipid peroxidation in diabetic rats [47]. It has also been reported that dietary supplementation with $\beta$-carotene could reduce plasma triglycerides and other indices of diabetic risk which may in turn, reduce the occurrence of 
diabetic vascular complications by normalizing lipid metabolism in diabetic patients [48].

Vitamin $\mathrm{C}$ was found to significantly reduce the increased levels of blood hydroperoxide, glucose, cholesterol, triglycerides and lowdensity lipoprotein (LDL) as well as restoring and reconstituting polyfunctional, long-lived $T$ cells in diabetic rats [49]. In another study, the administration of vitamin $\mathrm{C}$ to diabetic rats resulted in the restoration of basal metabolic rate and improvement of lipid profile, a risk factor for cardiovascular diseases [50]. However, some clinical studies conducted using human subjects showed that consumption of vitamin $\mathrm{C}$ decreased blood glucose and lipids in patients with type 2 diabetes and hence, could help to reduce the risk of complications $[51,52]$. Similarly, oral supplementation of vitamin $\mathrm{C}$ with metformin has been shown to decrease fasting blood sugar, post meal blood sugar and improved glycosylated haemoglobin in diabetic patients [53]. Also, vitamin C as add on therapy to oral hypoglycemic agent was shown to improve lipid profile to the desirable levels and hence, could help to reduce the risk of diabetic complications [54]. The direct inhibition of aldose reductase in human erythrocytes by vitamin $\mathrm{C}$ has also been established and this provides a rationale for the use of oral vitamin C supplements in diabetes [55]. Vitamin C supplementation has been shown to recover apoptotic rates in the prostate of diabetic rats [1]. Supplementation with vitamin C has been shown to improved erythrocyte deformabilty in diabetic rats [56]. In another study, vitamin $\mathrm{C}$ was able to reduce the number of abnormal sperm and increased testosterone and $\mathrm{LH}$ levels as well as seminiferous tubular diameter in the epidiymis of diabetic rats [32].

Vitamin E reduced systolic and diastolic pressure probably by interfering with some pathways that contribute to the occurrence of hypertension in diabetic conditions [57]. Vitamin $E$ has been reported to improve beta cell function and insulin resistance in tissues as well as reducing blood glucose and glycated haemoglobin levels [58]. Apart from the reduction of blood glucose and glycated haemoglobin, tocotrienols also reduced plasma LDL-cholesterol and triglycerides and increased HDL-cholesterol [59]. The long term administration of vitamin $\mathrm{E}$ has been reported to improve insulin sensitivity and may improve endothelial function [60]. Vitamin $E$ supplementation has also been shown to provide significant cardio protective effects against cardiac dysfunction and concomitant myocardial oxidative stress induced by type 1 diabetes [31].
Vitamin $E$ has been shown to reduce ROS generation and damaging oxidative substances and maintain membrane fluidity in the brain of diabetic rats [61]. In another study, it has been suggested that the antioxidant potential of both the isomers of vitamin $\mathrm{E}$ may be responsible for the protection against intra-cerebroventricular STZ - induced oxidative stress by possibly increasing the endogenous defensive capacity of the brain [62].

Tocotrienols exhibit antioxidant activities and it activities are mediated through the induction of antioxidant enzymes such as SOD, NADPH: quinine oxidoreductase and glutathione peroxidase which quench free radicals such as superoxide ions [59]. Vitamin E supplementation was shown to prevent glucose-induced lipid peroxidation in rat mesangial cells and hence, could limit the development of glomerulosclerosis in diabetic nephropathy [63]. Favourable effect of vitamin $E$ on oxidative stress in the renal cortex of diabetic rats has been shown [64].

Vitamin E supplementation has also been shown to significantly lower lipid peroxidation and lipid levels in the blood of diabetic patients [65]. It has been reported that the preventive effect of vitamin $E$ supplementation in diabetic complications is possibly through a decrease in lipid peroxidation [66]. Vitamin $E$ supplementation reduced glycaemia and glycated haemoglobin levels significantly and had a neuro-protective effect on the total myenteric population, without affecting intestinal area or thickness of the intestinal wall or muscular tunic [27]. High dose of vitamin-E supplementation in diabetic rats improved motor and sensory conduction velocity in tibial and sural nerves by $50 \%$ [67]. Vitamin $E$ has been shown to reverse the pathological changes in diabetic neuropathy and thereby serves as a safe and inexpensive supplement that can be used for prevention/treatment of diabetic neuropathy [11]. Vitamin $E$ has been shown to favourably decrease microalbuminemia in diabetic subjects, hence showing nephroprotective activity [68]. Vitamin $E$ can also help in the reduction peripheral neuropathic pain in diabetes [69] and its consumption has also been able to attenuate elevated plasma lipid profile and reduce plasma levels of C-reactive protein (CRP) and oxidizedlow-density lipoproteins (Ox-LDL) in diabetic rats [70], hence could be helpful in the management of cardiovascular disease, a diabetic complication. In other words, in diabetic subjects, the administration of vitamin $E$ produced no effect on cardiovascular disease outcomes or nephropathy [71]. 
Table 1: Mode of actions of antioxidant vitamins

\begin{tabular}{|c|c|}
\hline Antioxidant vitamins & Mode of antioxidant functions \\
\hline Vitamin A (Beta carotene) & $\begin{array}{l}\text { - } \text { Fat-soluble chain breaking antioxidant (lipophilic } \\
\text { radical-scavenging antioxidant) } \\
\text { - } \quad \text { Inhibition of hydroxyl and superoxide anion radicals } \\
\text { - } \quad \text { Quenches singlet oxygen } \\
\text { - } \quad \text { Scavenger of peroxyl radical at low oxygen tension } \\
\text { - Induces glutathione production in the cells }\end{array}$ \\
\hline Vitamin C (Ascorbic acid) & $\begin{array}{l}\text { - Water soluble chain breaking antioxidant (hydrophilic } \\
\text { radical-scavenging antioxidant) } \\
\text { - Directly scavenges hydroxyl and superoxide anion } \\
\text { radicals as well as hydrogen peroxide. } \\
\text { - } \text { Acts as a reducing agent } \\
\text { - Neutralizes oxidants from stimulated neutrophils } \\
\text { Neutralizes the radical form of other antioxidants such } \\
\text { as glutathione radical and vitamin E radical and } \\
\text { contribute to regeneration of these antioxidants. } \\
\text { Acts as substrate for the antioxidant enzyme, } \\
\text { ascorbate peroxidase in plants }\end{array}$ \\
\hline $\begin{array}{l}\text { Vitaimin E (Tocopherol and } \\
\text { Tocotrienol) }\end{array}$ & $\begin{array}{ll}\text { - } & \text { Fat-soluble chain breaking antioxidant } \\
\text { - } & \text { Scavenger of superoxide anion radicals } \\
\text { - } & \text { Scavenges peroxyl radical at high oxygen tension } \\
\text { - } & \text { Lipid peroxidation inhibition }\end{array}$ \\
\hline
\end{tabular}

The modes of action of these vitamins are summarized in Table 1.

The treatment of diabetic rats with vitamin C and vitamin $E$ singly ameliorated thermal hyperalgesia and cold allodynia [45] and also improved oxidative damage and nephropathy in diabetic rats [46]. Combined treatment with vitamins $\mathrm{E}$ and $\mathrm{C}$ in pregnant diabetic rats decreased fetal malformation rate and tissue damage caused by oxidative stress [72]. In another study, vitamins $C$ and $E$ significantly reduced the urinary albumin excretion rate (UAER) and glycosylated haemoglobin in patients with diabetic nephropathy [29]. Vitamin $\mathrm{C}$ and $\mathrm{E}$ have been helpful in alleviating renal degeneration by protecting the glomerular structures from oxidative injury [73] and also decreased lipid peroxidation and improved the activities of antioxidant enzymes in the kidneys $[28,74]$, liver $[75,76]$, brain, lens, and testes [76] of diabetic rats. Both vitamins $C$ and $E$ have been helpful in the decrease of kidney weight and glomerular basement membrane (GBM) thickness. This shows the potentials of antioxidant vitamins in the protection against the development of diabetic nephropathy [74].

\section{CONCLUSION}

Active reactive oxygen species are produced as a result of high glucose (hyperglycaemia) levels in the body. Indeed, diabetes constitutes a multiple source of free radicals due to prolonged exposure to hyperglycermia and reduction in the capacities of antioxidant defense systems. Body systems are negatively affected as a result of prolong hyperglycaemia oxidative stress which in turn leads to diabetic complications. As evident from literature, exploration of the potentials of natural antioxidants such as vitamins $A, C$ and $E$ have been helpful in the negation of excess ROS production and acts as counteractive agents against hyperglycaemia-induced oxidative damage in the body. Further studies are needed to establish the various mechanisms by which these vitamins produce their effects on diabetic conditions. In addition, since there are few studies on the antioxidant potentials of antioxidant vitamins using human subjects from available literature, more clinical studies are needed to support the claims from animal studies.

\section{ACKNOWLEDGEMENT}

We would like to thank the North-West University and National Research Foundation (NRF) of South Africa for providing funding for this work through Prof Emmanuel Mukwevho. We also appreciate Cape Peninsula University of Technology, South Africa for funding through Prof Oluwafemi Oguntibeju and Dr Nicole Brooks.

\section{DECLARATIONS}

\section{Conflict of Interest}

No conflict of interest associated with this work. 


\section{Contribution of Authors}

The authors declare that this work was done by the authors named in this article and all liabilities pertaining to claims relating to the content of this article will be borne by them.

\section{REFERENCES}

1. Gobbo MG, Ribeiro DL, Taboga SR, De Almeida EA, Góes RM. Oxidative stress markers and apoptosis in the prostate of diabetic rats and the influence of vitamin $C$ treatment. J Cell Biochem 2012; 113: 2223-2233.

2. Saravanan G, Ponmurugan P. Antidiabetic effect of Sallylcysteine: Effect on thyroid hormone and circulatory antioxidant system in experimental diabetic rats. $J$ Diabetes Complicat 2012; 26: 280-285.

3. Hikino H, Kobayashi M, Suzuki Y, Konno C. Mechanisms of hypoglycaemic activity of a conitan A, a glycan from Aconitum carmichaeli roots. J Ethnopharmacol 1989; 25: 295-304.

4. Kalaivanan K, Pugalendi KV. Antihyperglycaemic effect of the alcoholic seed extract of Swietenia macrophylla on streptozotocin-diabetic rats. Pharmacog Res 2011; 3: 67-71.

5. Danaei G, Finucane MM, Lu Y, Singh GM, Cowan MJ, Paciorek CJ, Lin JK, Farzadfar F, Khang YH, Stevens GA, Rao M, Ali MK, Riley LM, Robinson CA, Ezzati M. National, regional, and global trends in fasting plasma glucose and diabetes prevalence since 1980: systematic analysis of health examination surveys and epidemiological studies with 370 country-years and 2.7 million participants. Lancet 2011; 378: 31-40.

6. World Health Organization. Global status report on noncommunicable diseases 2010. Geneva.

7. Gale AM. The discovery of type I diabetes. Diabetes 2001; 50: 217-226.

8. Ayeleso AO, Oguntibeju OO, Brooks N. Flavonoids and their antidiabetic potentials. In: Bioactive Phytochemicals: Perspectives for Modern Medicine, Volume 1. Daya Publishing House, New Delhi 2012; ISBN: 978-81-7035-779.

9. Unwin N, Whiting D, Gan D, Jacqmain O, Ghyoot G. IDF Diabetes Atlas (4th ed.) International Diabetes Federation, Brussels, Belgium. 2009.

10. Islam M. Effects of the aqueous extract of white tea (Camellia sinensis) in a streptozotocin-induced diabetes model of rats. Phytomedicine 2011; 19: 25-31.

11. Algaidi S. The effect of antioxidants on experimentally induced diabetic peripheral neuropathy in adult male albino rats. J Am Sci 2011; 7: 671-677.

12. Kuchake VG, Upasani $C D$. Evaluation of protective effect of antioxidant vitamins in patients with diabetic nephropathy. Asian J Pharm Clin Res 2011; 4: 52-54.

13. Pari L, Latha M. Protective role of Scoparia dulcis plant extract on brain antioxidant status and lipidperoxidation in STZ diabetic male Wistar rats. BMC Complement Altern Med 2004; 4: 16, doi: 10.1186/1472-6882-4-16.
14. Uttara B, Singh AV, Zamboni P, Mahajan RT. Oxidative stress and neurodegenerative diseases: a review of upstream and downstream antioxidant therapeutic options. Curr Neuropharmacol 2009; 7: 65-74.

15. Lazo-De-La-Vega-Monroy MI, Fernández-Mejía C. Oxidative stress in diabetes mellitus and the role of vitamins with antioxidant actions, oxidative stress and chronic degenerative diseases - a role for antioxidants, Dr. Jose Antonio Morales-Gonzalez (Ed.), 2013; ISBN: 978-953-51-1123-8, InTech, DOI:10.5772/51788.

16. Veskoukis AS, Kyparos A, Nikolaidis MG, Stagos D, Aligiannis N, Halabalaki M, Chronis K, Goutzourelas N, Skaltsounis $L$, Kouret $D$. The antioxidant effects of a polyphenol-rich grape pomace extract in vitro do not correspond in vivo using exercise as an oxidant stimulus. Oxid Med Cell Longev 2012; 2012: 185867.

17. Wall SB, Oh JY, Diers AR, Landar A. Oxidative modification of proteins: an emerging mechanism of cell signaling. Front Physiol 2012; 3: 369.

18. Erejuwa OO. Oxidative Stress in diabetes mellitus: is there a role for hypoglycaemic drugs and/or antioxidants? Oxidative stress and diseases, Volodymyr

19. I. Lushchak and Dmytro V. Gospodaryov (Ed.) 2012; ISBN: 978-953-51-0552-7.

20. Tirgar $P$, Jadav $P$, Sheth $D$, Desai T, Tirgar $P R$, Jadav $P D$, Sheth MDB. Therapeutic role of anti-oxidant properties of Emblica officinalis (amla) in streptozotocin induced type 1 diabetic rats. Pharmacologyonline 2010; 1: $728-743$.

21. Baynes JW. Role of oxidative stress in development of complications in diabetes. Diabetes 1991; 40: 405-412.

22. Wolff SP, Jiang ZP, Hunt JV. Protein glycation and oxidative stress in diabetes mellitus and ageing. Free Radic Biol Med 1991; 10: 339-352.

23. Glugliano $D$, Eriello $A$, Paolosso G. Oxidative stress and diabetic vascular complications. Diabetes Care 1996; 19: 257-267.

24. Al-Faris NA, Al-Sawadi AD, Alokail MS. Effect of Samh seeds supplementation (Mesembryanthemum forsskalei Hochst) on liver enzymes and lipid profiles of streptozotocin (STZ)-induced diabetic Wistar rats. Saudi J Biol Sci 2010; 17: 23-28.

25. Tiwari BK, Pandey KB, Abidi AB, Rizvi SI. Markers of Oxidative Stress during diabetes ellitus. J Biomarkers 2013; 2013: 378790.

26. Bierhaus A, Hofmann MA, Ziegler R, Nawroth PP. AGEs and their interaction with AGE-receptors in vascular disease and diabetes mellitus. I. The AGE concept. Cardiovasc Res 1998; 37: 586-600.

27. Ziegler D, Sohr CG, Nourooz-Zadeh J. Oxidative stress and antioxidant defense in relation to the severity of diabetic polyneuropathy and cardiovascular autonomic neuropathy. Diabetes Care 2004; 27: 2178-2183.

28. Roldi L, Pereira R, Tronchini E, Rizo G, Scoaris C, Zanoni J, Natali M. Vitamin E (a-tocopherol) supplementation in diabetic rats: effects on the proximal colon. BMC Gastroenterol 2009; 9: 88.

Trop J Pharm Res, June 2016; 15(6): 1346 
29. Özkaya $D$, Naziroğlu M, Armağan A, Demirel A, Köroglu $B k$, Çolakoğlu N, Kükner A, Sönmez TT. Dietary vitamin $C$ and $E$ modulates oxidative stress induced-kidney and lens injury in diabetic aged male rats through modulating glucose homeostasis and antioxidant systems. Cell Biochem Funct 2011; 9: 287-293.

30. Kuchake VG, Upasani CD. Effect of vitamin $E$ and $C$ plus reduced glutathione in treatment of diabetic nephropathy. Int J Pharma Res Rev 2013; 2: 1-5.

31. Levinthal GN, Tavill, AS. Liver disease and diabetes mellitus. Clin Diabetes 1999; 17: 73-93.

32. Hamblin M, Smith HM, Hill MF. Dietary supplementation with vitamin $E$ ameliorates cardiac failure in type 1 diabetic cardiomyopathy by suppressing myocardial generation of 8-iso-prostaglandin F2 [alpha] and oxidized glutathione. J Card Fail 2007; 13: 884-892.

33. Fernandes GS, Fernandez CD, Campos KE, Damasceno DC, Anselmo-Franci JA, Kempinas WD. Vitamin C partially attenuates male reproductive deficits in hyperglycemic rats. Reprod Biol Endocrinol 2011; 9: 100, doi: 10.1186/1477-7827-9-100.

34. Edem DO. Vitamin A: A Review. Asian J Clin Nutr 2009; 1: 65-68.

35. Pavia SA, Russell RM. Beta-carotene and other carotenoids as antioxidants. J Am Coll Nutr 1999; 18 : 426-433.

36. Purev E, Soprano DR, Soprano KJ. Effect of all-trans retinoic acid on telomerase activity in ovarian cancer cells. J Exp Clin Cancer Res 2004; 23: 309-316.

37. Zerin MA, Karakilcik M, Bitiren D, Musa A, Ozgonol S, Selek $Y$, Nazligul A, Uzunko Y. Vitamin $C$ modulates oxidative stress-induced colitis in rats. Turk J Med Sci 2010; 40: 871-879.

38. Djurašević SF, Djordjevic J, Drenca T, Jasnić N, Cvijić G. Influence of vitamin $C$ supplementation on the oxidative status of rat liver. Arch Biol Sci Belgrade 2008; 60: 169173.

39. Brigelius-Flohe' $R$, Traber MG. Vitamin E: function and metabolism. FASEB J 1999; 13: 1145-1155.

40. Blokhina O, Virolainen E, Fagerstedt KV. Antioxidants, oxidative damage and oxygen deprivation stress: $A$ review 2003; Ann Bot 91: 179-194.

41. Bebe FN, Panemangator M. Pesticides and essential minerals modify endogenous antioxidants and cytochrome P450 in tissues of rats. J Environ Sci Health 2005; 40: 769-784.

42. Astaneie F, Afshari M, Mojtahedi A, Mostafalou S, Zamani Mj, Larijani B, Abdollahi M. Total antioxidant capacity and levels of epidermal growth factor and nitric oxide in blood and saliva of insulin-dependent diabetic patients. Arch Med Res 2005; 36: 376-381.

43. Babujanarthanam $R$, Kavitha $P$, Mahadeva Rao $U$, Pandian MR. Quercitrin a bioflavonoid improves the antioxidant status in streptozotocin induced diabetic rat tissues. Mol Cell Biochem 2011; 358: 121-129.

44. Zobali F, Avci A, Canbolat O, Karasu C. Effects of vitamin $A$ and insulin on the antioxidative state of diabetic rat heart: a comparison study with combination treatment. Cell Biochem Funct 2002; 20: 75-80.

45. Sharma M, Katyal T, Grewal G, Behera D, Budhiraja R. Effect of antioxidants such as $\beta$-carotene, vitamin $C$ and vitamin $E$ on oxidative stress, thermal hyperalgesia and cold allodynia in streptozotocin induced diabetic rats. The Internet Journal of Pharmacology 2008; 6.

46. Katyal T, Sharma M, Sidhu K, Behera D, Ramji Das Budhiraja RD. Beneficial effects of antioxidants on oxidative stress and diabetes-induced experimental nephropathy. Pharmacologyonline 2009; 1: 252-263.

47. Maritim A, Dene BA, Sanders RA, Watkins JB 3rd. Effects of beta-carotene on oxidative stress in normal and diabetic rats. J Biochem Mol Toxicol 2002; 16: 203208.

48. Seo JS, Lee KS, Jang JH, Quan Z, Yang KM, Burri BJ. The effect of dietary supplementation of $\beta$-carotene on lipid metabolism in streptozotocin-induced diabetic rats. Nutr Res, 2004; 24: 1011-1021.

49. Badr G, Bashandy S, Ebaid H, Mohany M, Sayed D. Vitamin $C$ supplementation reconstitutes polyfunctional $T$ cells in streptozotocin-induced diabetic rats. Eur J Nutr 2011; DOI 10.1007/s00394-011-0176-5.

50. Owu DU, Antai $A B$, Udofia KH, Obembe $A O$, Obasi $K O$, Eteng MU. Vitamin $C$ improves basal metabolic rate and lipid profile in alloxan-induced diabetes mellitus in rats. $J$ Biosci 2006; 31: 575-579.

51. Afkhami-Ardekani M, Shojaoddiny-Ardekani A. Effect of vitamin $C$ on blood glucose, serum lipids \& serum insulin in type 2 diabetes patients. Indian J Med Res 2007;126: 471-474.

52. Vaksh S, Pandey M, Zingade US, Reddy VS. The effect of vitamin-c therapy on hyperglycemia, hyperlipidemia and non high density lipoprotein level in type 2 diabetes. Int J Life Sc Bt Pharm Res 2013; 2.

53. Dakhale GN, Chaudhari HV, Shrivastava $M$. Supplementation of vitamin $C$ reduces blood glucose and improves glycosylated hemoglobin in type 2 diabetes mellitus: A Randomized, double-blind study. Adv Pharmacol Sci 2011, 2011: 195271.

54. Rekha Nayaka MR. A comparative trial on the efficacy of vitamin $c$ as add on therapy to the oral hypoglycemic agent on serum lipid level in newly diagnosed type 2 diabetes mellitus. Int J Pharmacol Res 2015; 5: ISSN: 2277-3312.

55. Vincent TE, Mendiratta S, May JM. Inhibition of aldose reductase in human erythrocytes by vitamin C. Diabetes Res Clin Pract 1999; 43:1-8.

56. Comu FM, Ozturk L, Alkan M, Pampal K, Arslan M, Isik $B$, Atac MS, Yilmaz D. Investigation of the effects of propofol and vitamin $C$ administration on erythrocyte deformability in rats with streptozotocin-induced. Bratisl Lek Listy 2014; 115: 400-404.

57. Haidara MA, Mikhailidis DP, Rateb MA, Ahmed ZA, Yassin HZ, Ibrahim IM, Rashed LA. Evaluation of the effect of oxidative stress and vitamin $E$ supplementation on renal function in rats with streptozotocin-induced 
Type 1 diabetes. J Diabetes Complicat 2009; 23: 130136.

58. Naziroglu M, Simsek M, Simsek H, Aydilek N, Özcan Z, Atllgan $R$. The effects of hormone replacement therapy combined with vitamins $C$ and $E$ on antioxidants levels and lipid profiles in postmenopausal women with type 2 diabetes. Clinica Chimica Acta 2004; 344(1-2): 63-71.

59. Aggarwal BB, Sundaram C, Prasad S, Kannappan. Tocotrienols, the vitamin $E$ of the 21st century: its potential against cancer and other chronic diseases. Biochem Pharmacol 2010; 80: 1613-1631.

60. Skyrme-Jones RAP, O'brien RC, Berry KL, Meredith IT. Vitamin $E$ supplementation improves endothelial function in type I diabetes mellitus: a randomized, placebo-controlled study. J Am Coll Cardiol 2000; 36: 94-102.

61. Hong JH, Kim MJ, Park MR, Kwag OG, Lee IS, Byun BH, Lee SC, Lee KB, Rhee SJ. Effects of vitamin $E$ on oxidative stress and membrane fluidity in brain of streptozotocin-induced diabetic rats. Clinica Chimica Acta 2004; 340: 107-115.

62. Tiwari V, Kuhad A, Bishnoi M, Chopra K. Chronic treatment with tocotrienol, an isoform of vitamin $E$, prevents intracerebroventricular streptozotocin-induced cognitive impairment and oxidative-nitrosative stress in rats. Pharmacol Biochem Behav 2009; 93: 183-189.

63. Trachtman $H$. Vitamin $E$ prevents glucose-induced lipid peroxidation and increased collagen production in cultured rat mesangial cells. Microvasc Res 1994; 47: 232-239.

64. Jachec W, Tomasik A, Tarnawski R, Chwalinska E. Evidence of oxidative stress in the renal cortex of diabetic rats: favourable effect of vitamin $E$. Scand $J$ Clin Lab 2002; 62: 81-88.

65. Jain SK, Mcvie R, Jaramillo JJ, Palmer M, Smith $T$, Meachum ZD, Little RL. The effect of modest vitamin $E$ supplementation on lipid peroxidation products and other cardiovascular risk factors in diabetic patients. Lipids 1996; 31: S87-S90.

66. Niedowicz DM, Daleke DL. The role of oxidative stress in diabetic complications. Cell Biochem Biophys 2005; 43: 289-330.
67. Van Dam PS, Bravenboer B, Van Asbeck BS, Marx JJ, Gispen WJ. High rat food vitamin $E$ content improves nerve function in streptozotocin-diabetic rats. Eur $J$ Pharmacol 1999; 376: 217-222.

68. Hirnerová E, Krahulec B, Strbová L, Stecová A, Dekrét J, Hájovská $A$. Effect of vitamin $E$ therapy on progression of diabetic nephropathy. Vnitr Lek 2003; 49: 529-534.

69. Babaei-Balderlou F, Zare S, Heidari R, Farrokhi $F$. Effects of melatonin and vitamin $E$ on peripheral neuropathic pain in streptozotocin-induced diabetic rats. Iran J Basic Med Sci 2010; 13: 1-8.

70. Shirpoor A, Norouzi L, Nemati S, Khadem Ansari MH. Protective effect of vitamin $E$ against diabetes-induced oxidized Idl and aorta cell wall proliferation in rat. Iran Biomed J 2015; 19: 117-123.

71. Lonn E, Yusuf S, Hoogwerf B, Pogue J, Yi Q, Zinman B, Bosch J, Dagenais G, Mann JF, Gerstein HC. Effects of vitamin $E$ on cardiovascular and microvascular outcomes in high-risk patients with diabetes: results of the HOPE study and MICROHOPE substudy. Diabetes Care 2002; 25: 1919-1927.

72. Cederberg J, Simán CM, Eriksson UJ. Combined treatment with vitamin $E$ and vitamin $C$ decreases oxidative stress and improves fetal outcome in experimental diabetic pregnancy. Pediatr Res 2001; 49: 755-762.

73. Kukner A, Colakoglu N, Naziroglu M, Firat T. The effects of combined vitamin $C$ and $E$ in Streptozotocin-induced diabetic rat kidney. Clin Rev Opinion 2009; 1: 029-036.

74. Kedziora-Kornatowska K, Szram S, Kornatowski T, Szadujkis-Szadurski L, Kedziora J, Bartosz G. Effect of vitamin $E$ and vitamin $C$ supplementation on antioxidative state and renal glomerular basement membrane thickness in diabetic kidney. Nephron Exp Nephrol 2003; 95: e134-e143.

75. Garg MC, Bansal DD. Protective antioxidant effect of vitamins $C$ and $E$ in streptozotocin induced diabetic rats. Indian J Exp Biol 2000; 38: 101-104.

76. Naziroğlu M, Butterworth PJ, Sonmez TT. Dietary vitamin $C$ and $E$ modulates antioxidant levels in blood, brain, liver, muscle, and testes in diabetic aged rats. Int $J$ Vitam Nutr Res 2011; 81: 347-357. 